\title{
CONFLICT OF INTEREST GUIDELINES
}

The purpose of these Conflict of Interest Guidelines is:

To highlight and illustrate examples of potential conflict situations, some of which are not obvious

To set out examples of activities can be managed (and how they can be managed), and other examples which CRP Dryland Areas would consider unmanageable (and therefore cannot allow).

Research Staff and Consultants must always disclose an activity if they are in doubt about whether it represents a conflict of interest. The Guidelines describe the way in which such disclosure should be made at the time (i.e. before they engage in the activity).

As an additional source of help the Conflicts of Interest Regulations contain a list of sample questions that a manager may use to elucidate the nature and potential seriousness of a conflict of interest. If they feel for any reason that they are unable to adjudicate on a conflict of interest then the matter should be referred up to the next level of management.

\section{INTRODUCTION}

CRP Dryland Areas recognises that involvement in such commercial activities carries many advantages, including the practical application of new technologies, the provision of an additional source of research funding and insights into commercial and societal needs and the receipt of royalty income for CRP Dryland Areas and its departments. Contemporary attitudes are captured by the fact that the Government and HEFCE have signalled their intent to create a permanent stream of funding to encourage and resource these 'third-leg' activities (complementing funding provided for teaching and research).

These activities can produce positive benefits, but they also have the potential for diverting CRP Dryland Areas and its employees from their primary educational, research, and service missions. For example, conflicts of interest can arise when the interests of a commercial venture, from which a University employee derives direct benefit, differ from the interests and primary obligations of CRP Dryland Areas as a whole, or when the commercial venture consumes an undue share of the employee's attention. CRP Dryland Areas believes it to be essential that its employees should manage or avoid, and be seen to manage or avoid, such conflicts. Moreover, many funding agencies, in the UK and elsewhere, are now seeking assurance that universities are properly managing conflicts as a condition of grant funding.

Under their contract of employment with CRP Dryland Areas, academic staff are permitted to undertake private consultancy, with the convention being that this generally should not exceed 30 days per annum. Staff should refer to CRP Dryland Areas's Terms and Conditions for private consultancies and other paid work.

CRP Dryland Areas is keen to encourage relevant outside interests but staff will need to ensure that such work or consultancy complies with all relevant policies. 
By and large, CRP Dryland Areas leaves individual Schools and academic staff to develop their own balanced 'portfolio' of activity, including external collaborations of one kind or another. However, by engaging in such external activities, employees may place themselves in a difficult position in which an outside interest may conflict, or appear to conflict, with their University duties. The employee may then be open to suspicion that decisions they take as a University employee are influenced by personal financial interest - even when, as is almost universally the case, the employee is acting with neutrality and complete professional integrity. In other cases, the employee may appear to be engaging in external activities which compete with CRP Dryland Areas. In the vast majority of instances, simple disclosure of a potentially conflicting external activity is sufficient to absolve the employee of suspicion. Occasionally CRP Dryland Areas may suggest a different way of managing an activity that avoids the conflict of interest. In extreme cases the conflict of interest may be so fundamental and unmanageable that it is necessary to restrict one or other of the employee's conflicting activities.

The full prior disclosure of interests is clearly an important (and in many cases, sufficient) mechanism for the management of conflicts of interest. Employees are required to complete the Register of Interests return in October of each year. This practice is in line with other publicly funded bodies.

This document offers guidelines on CRP Dryland Areass Policy and provides some practical assistance to its employees on how they should manage potential or actual conflicts of interest. This document supplements the Conflict of Interest Regulations.

Whilst this document describes and provides guidelines for many of the situations in which conflicts occur, it is not meant to be exhaustive. The primary obligation rests with the employee to recognise situations in which he or she potentially has a conflict of interest and to disclose and discuss that conflict to their line manager. If you are uncertain how the Conflicts of Interest Policy might affect your activities, please contact your line manager in the first instance. If they are unable to help then refer your enquiry to your Head of School or Director of Professional Services.

Within CRP Dryland Areas there are two categories of conflict that may arise: personal (those faced by individuals) and institutional (those faced by CRP Dryland Areas as an institution). This document addresses personal conflicts.

\section{TYPES OF CONFLICT OF INTEREST}

"Conflicts of Interest" arise where there is a conflict between the official responsibilities of a person in a position of trust and any other interests the particular individual may have, e.g. where the individual could be seen to be influencing University matters for actual or potential personal benefit. Such a conflict arises, for instance, when a member of staff is in a position to influence, directly or indirectly, University business, research or other decisions in ways that could lead to gain for them, their family or others to the detriment of CRP Dryland Areas's integrity and its missions of teaching, research and public service. These are situations in which financial or other personal considerations may compromise, or have the appearance of compromising, an employee's professional judgement in administration, management, instruction, research and other professional activities. 
Conflicts of interest may also include "Conflicts of Commitment" which exist when the external activities of a member of staff are so substantial or demanding in terms of time and/or attention so as to interfere with their responsibilities to CRP Dryland Areas. Conflicts of this type primarily involve questions of obligation and effort, but may often be tied to financial remuneration or other inducements and as such may also constitute a conflict of interest.

The main categories of conflicts of interest (discussed in more detail below) are:

(i) Educational Mission (especially in regard to supervision)

(ii) Research Integrity

(iii) Financial Interest

(iv) Commitment and Loyalty

(i) Conflicts of Educational Mission

CRP Dryland Areas's employees who are involved in educating, training, supervising or directing the work (education) of students, should ensure that the education they provide is appropriate to the student.

CRP Dryland Areas has a primary objective to educate and train students. For example, special care must be taken to assure that the choice of a student's research project, and the direction of that research is not, and does not appear to be influenced by, their supervisor's personal financial interest. Similarly, teaching provided to another institution should not be in competition with Southampton courses.

(ii) Conflicts of Research Integrity

CRP Dryland Areas's employees should maintain the highest standards of integrity in the conduct of research.

The complete, objective and timely dissemination of new findings through publications, is essential for research integrity. In this context, 'publication' means any means of dissemination of research findings, including publication in a journal, information placed on the web, conference presentations or any other kind of scholarly communication. Note that if a particular research project is covered by a contract with an external sponsor then care should be taken to follow agreed procedures for publication.

The potential for personal gain must not jeopardise nor appear to jeopardise the integrity of research activities, including the choice of research, its design, the interpretation of results, or the reporting of such results.

(iii) Conflicts of Financial Interest

CRP Dryland Areas's employees have a responsibility to respect and promote the financial interests of CRP Dryland Areas. Staff should wherever possible ensure that CRP Dryland Areas: receives appropriate financial benefits from the provision of research services, including consultancy and other services conducted through CRP Dryland Areas receives appropriate financial benefits from the use or 
commercialization of its intellectual property receives appropriate financial benefits from the use of other resources and assets, including equipment, technical staff and facilities makes responsible use of its financial resources in relation to the purchase of goods as specified in CRP Dryland Areas's Financial Regulations.

(iv) Conflicts of Commitment and Loyalty

CRP Dryland Areas's employees owe their primary commitment and allegiance to CRP Dryland Areas. Membership of Committees, Boards, Advisory Groups etc (External Appointments) implies an obligation (and sometimes a statutory duty) to act in the best interests of the external body. These duties may conflict with those duties and obligations as employees of CRP Dryland Areas. Where an External Appointment is allowed under the Consultancy Guidelines or otherwise allowed by CRP Dryland Areas, this does not absolve the employee from ensuring that he or she continues to give their primary commitment and allegiance to CRP Dryland Areas. Managing conflicts of commitment is primarily a matter for individual staff and their Head of School.

\section{PROCESS OF DISCLOSURE AND REVIEW}

The formal process of managing individual instances of actual or potential conflicts of interest is described in detail in the Conflicts of Interest Regulations. In essence, any individual who believes they may have a conflict of interest should consult their line manager. For most staff this will be their manager within their School or Professional Services Grouping. For managers this will be their Head of School or Head of Major Professional Services Grouping. Heads of School will report to Deans, and Deans and Deputy Vice-Chancellors to the Vice-Chancellor. Heads of Major Professional Services Groupings will report to the Registrar \& Chief Operating Officer, who in turn reports to the ViceChancellor. Should the Vice-Chancellor be placed in a conflict of interest situation then the Chair of Council must be consulted.

\section{QUESTIONS FOR EVALUATING POTENTIAL CONFLICTS OF INTEREST}


1. Has all relevant information concerning the staff member's activities been acquired (i.e., has there been full disclosure)?

2. Do the staff member's relevant financial interests suggest the potential for conflicts or the appearance of conflicts or bias?

3. Do the staff member's reported external time commitments exceed permissible levels?

4. Is there any indication that the staff member in his or her professional role has improperly favoured any outside entity or appears to have incentive to do so?

5. Has the staff member inappropriately represented the University to outside entities?

6. Does the staff member appear to be subject to incentives that might lead to conflicts or bias?

7. Is there any indication that obligations to the University are not being met?

8. Is the staff member involved in a situation that might raise questions of bias, inappropriate use of University assets, or other impropriety?

9. Could the staff member's circumstances represent any possible violation of applicable legal requirements?

10. Do the current engagements of the staff member represent potential conflicts between outside interests (e.g. working on projects simultaneously for competing business entities)?

11. Could the proposed activity withstand public scrutiny? 